\title{
First-Principles Study of ZnIn2Te4 and HgIn2Te4 Defect-Chalcopyrite Semiconductors Under Different Pressures: Electronic, Elastic, And Optical Properties
}

SATISH CHANDRA ( $\nabla$ chandra.satish1989@gmail.com )

Madan Mohan Malaviya University of Technology https://orcid.org/0000-0002-8719-1887

V. Kumar

Indian Institute of Technology

\section{Research Article}

Keywords: first-principle calculations, defect chalcopyrite, electronic properties, Debye temperature, and optical properties

Posted Date: September 21st, 2021

DOI: https://doi.org/10.21203/rs.3.rs-648445/v1

License: (c) (i) This work is licensed under a Creative Commons Attribution 4.0 International License.

Read Full License 
First-principles study of $\mathrm{ZnIn}_{2} \mathrm{Te}_{4}$ and $\mathrm{HgIn}_{2} \mathrm{Te}_{4}$ defect-chalcopyrite semiconductors under different pressures: Electronic, elastic, and optical properties

\author{
S. Chandra, ${ }^{1, *}$ and V. Kumar ${ }^{2}$ \\ ${ }^{1}$ Department of Electronics and Communication Engineering, Madan Mohan Malviya University \\ of Technology, Gorakhpur-273010 \\ ${ }^{2}$ Department of Electronics and Communication Engineering, Indian Institute of Technology \\ (Indian School of Mines), Dhanbad-826004 \\ *Corresponding email: chandra.satish1989@gmail.com
}

\begin{abstract}
First-principle calculations of electronic, elastic, and optical properties for $\mathrm{ZnIn} 2 \mathrm{Te}_{4}$ and $\mathrm{HgIn}_{2} \mathrm{Te}_{4}$ defect-chalcopyrite semiconductors have been performed using local density approximation (LDA). Computed energy bandgaps are $1.398 \mathrm{eV}$ and $1.101 \mathrm{eV}$, respectively, for $\mathrm{ZnIn}_{2} \mathrm{Te}_{4}$ and $\mathrm{HgIn}_{2} \mathrm{Te}_{4}$, which show the indirect bandgaps behavior. Elastic parameters and Debye temperature have also been investigated at $0,5,10,13$, and $14 \mathrm{GPa}$ pressures. Calculated results indicate that both semiconductors are covalent in nature at $0 \mathrm{GPa}$ and become ionic afterward. Optical parameters have also been examined under $0,5,10$, and $13 \mathrm{GPa}$ in the energy span of $0 \mathrm{eV}$ to $15 \mathrm{eV}$. The calculated values indicate that these semiconductors are mechanically stable up to $13 \mathrm{GPa}$ and become unstable at $14 \mathrm{GPa}$. The Calculated values of all parameters are compared with the available experimental and reported values at $0 \mathrm{GPa}$. A reasonable agreement has been obtained between them. The values of these parameters at 5, 10, 13, and $14 \mathrm{GPa}$ pressures are reported for the first time.
\end{abstract}

Keywords: first-principle calculations, defect chalcopyrite, electronic properties, Debye temperature, and optical properties. 


\section{Introduction}

Defect-chalcopyrites (DCs) are special type of semiconductors of $\mathrm{A}^{\mathrm{II}} \mathrm{B}_{2}{ }^{\mathrm{III}} \mathrm{C}_{4}{ }^{\mathrm{VI}}$ family, which have an ordered vacancy compounds (OCV) structure. They have potential applications in the areas of solar cells, optoelectronics, linear and nonlinear optical devices [1-9]. As a result, much emphasis has been placed on the experimental synthesis and structural characterization of these materials. Experimentally, the Bridgman and chemical vapor transport (CVT) methods have been used to investigate their properties, which are observed by X-ray diffraction and Raman scattering [1017]. Whereas theoretically, the density functional theory (DFT) has been used by different workers [2-5, 18-20]. Recently, the authors have also used the first-principle calculations to investigate the different linear properties of $\mathrm{LiGaS}_{2}, \mathrm{LiGaSe}_{2}, \mathrm{ZnGeN}_{2}$ semiconductors [21, 22], and functionalized graphene semiconductors [23]. Various linear [24] and nonlinear optical (NLO) properties [25] of chalcopyrites have also been studied using plasma oscillations theory of solid. So far, no work has been carried out under different pressures. In this paper, we have investigated the effect of pressure on various properties of $\mathrm{XIn}_{2} \mathrm{Te}_{4}(\mathrm{X}=\mathrm{Hg}, \mathrm{Zn}$ ) defect-chalcopyrites using first-principle calculations. The effect of the pressure on $C_{i j}, G, B, v, B / G$ ratio, $A$, and $\theta_{D}$ parameters have been studied at $0,5,10,13$, and $14 \mathrm{GPa}$. The values of lattice parameter (a, c), anion displacement parameters $\left(U_{x}, U_{y}\right.$, and $\left.U_{z}\right)$, bond lengths $\left(d_{X-T e}, d_{I n^{1}-T e}\right.$ and $\left.d_{I n^{2}-T e}\right)$, energy bandgap $\left(E_{g}\right)$, and density of states (DOS) have been calculated at ambient conditions. The optical properties have also been investigated in the energy range of $0 \mathrm{eV}$ to $15 \mathrm{eV}$ at pressures of 0,5 , 10 , and $13 \mathrm{GPa}$. The estimated values of all 23 parameters are reasonably agreed with the known experimental and theoretical data at $0 \mathrm{GPa}$. The calculated values of these parameters at 5, 10, 13, and 14 GPa pressures are reported for the first time. 


\section{Computational methods}

First-principle calculations within DFT have been done using Cambridge Sequential Total Energy Package (CASTEP) [26] code to estimate linear properties such as electronic, optical, and elastic properties of $\mathrm{XIn}_{2} \mathrm{Te}_{4}(\mathrm{X}=\mathrm{Zn}, \mathrm{Hg})$ under different pressures. The calculations are based on local density approximation (LDA) of the Ceperley and Alder scheme parameterized by Perdew and Zunger to define exchange-correlation functions [27, 28]. The non-conversing pseudopotentials [29] have been applied with $660 \mathrm{eV}$ cut-off energy for the plane-wave basis set. The reciprocal crystal lattice and Brillouin zone integration have been executed using Monkhorst-pack mesh of $3 \times 3 \times 3$ within the Broyden, Fletcher, Goldfarb, and Shanno (BFGS) scheme [30]. Throughout geometry optimization, ultrafine quality for convergence threshold has been applied wherein Hell-Feynman ionic force is $0.01 \mathrm{eV} / \AA$, maximum total energy $5 \times 10^{-6} \mathrm{eV} / \mathrm{atom}$, maximum ion displacement $5 \times 10^{-4} \AA$, and stress tolerance $0.02 \mathrm{GPa}$.

\section{Results and discussion}

\subsection{Structural properties}

Defect-chalcopyrite semiconductors with formula $\mathrm{XIn}_{2} \mathrm{Te}_{4}(\mathrm{X}=\mathrm{Zn}, \mathrm{Hg})$ have a body-centered tetragonal configuration with space group I-4 (\#82). Each unit of $\mathrm{XIn}_{2} \mathrm{Te}_{4}$ crystal contains two-X, four-In, and eight-Te atoms along with two vacancies per unit cell. Wyckoff atomic coordinates of $\mathrm{XIn} 2 \mathrm{Te}_{4}$ crystal are $\mathrm{X}(0,0,0), \operatorname{In}^{1}(0,0,0.5), \operatorname{In}^{2}(0,0.5,0.5)$ and $\mathrm{Te}\left(U_{x}, U_{y}, U_{z}\right)$, where $U_{x}, U_{y}$ and $U_{z}$ are anion displacement parameters in three axes. The value of lattice parameters has been calculated and listed in Table 1, which are in fair agreement with the available data reported experimentally and theoretically $[31,32]$. The tetragonal distortion $\eta(=\mathrm{c} / 2 \mathrm{a})$ is 1 for the ideal structure, whereas the calculated values of $\eta$ are 0.996 and 0.987 for $\mathrm{ZnIn}_{2} \mathrm{Te}_{4}$ and $\mathrm{HgIn}_{2} \mathrm{Te}_{4}$, respectively, which equivalent to 1 . This shows the presence of tetragonal distortion. The values 
of anion displacement parameters $\left(U_{x}, U_{y}\right.$, and $\left.U_{z}\right)$ and bond lengths $\left(d_{X-T e}, d_{I n^{1}-T e}\right.$ and $\left.d_{I n^{2}-T e}\right)$ for $\mathrm{ZnIn}_{2} \mathrm{Te}_{4}$ and $\mathrm{ZnIn}_{2} \mathrm{Te}_{4}$ have been determined and presented in Table 1 along with the known values $[8,19,33-35]$. They agree well with the available reported values in the case of $\mathrm{ZnIn}_{2} \mathrm{Te}_{4}$. However, the values of these parameters for $\mathrm{HgIn}_{2} \mathrm{Te}_{4}$ are not available for comparison. Further, Table 1 shows that the bond lengths $d_{I n^{1}-T e}$ and $d_{I n^{2}-T e}$ are larger than $d_{X-T e}$. Figures 1(a) and 1(b) display the approximate band structures of $\mathrm{ZnIn}_{2} \mathrm{Te}_{4}$ and $\mathrm{HgIn}_{2} \mathrm{Te}_{4}$, respectively. This shows that both crystals are direct bandgap semiconductors with a bandgap of $1.398 \mathrm{eV}$ and $1.101 \mathrm{eV}$ along $\Gamma-\Gamma$ direction, respectively for $\mathrm{ZnIn}_{2} \mathrm{Te}_{4}$ and $\mathrm{HgIn}_{2} \mathrm{Te}_{4}$ at ambient conditions. The estimated bandgap $E_{g}$ values are presented in Table 1, together with known data [7, 8, 19, 31-37]. The estimated values $a, c, U_{x}, U_{y}, U_{z}$, and $E_{g}$ are also in fair concordance with the existing reported and experimental data.

\begin{tabular}{|c|}
\hline Figs. 1 (a), 1 (b), and Fig. 1 \\
\hline Figs. 2 (a), 2 (b), and Fig. 2 \\
\hline Table 1
\end{tabular}

The density of states provides knowledge about a crystal's angular momentum character. The elements $\mathrm{Zn}, \mathrm{Hg}$, In, and Te have the electronic configurations [Ar] $3 \mathrm{~d}^{10} 4 \mathrm{~s}^{2},[\mathrm{Xe}] 4 \mathrm{f}^{14} 5 \mathrm{~d}^{10} 6 \mathrm{~s}^{2}$, $[\mathrm{Kr}] 4 \mathrm{~d}^{10} 5 \mathrm{~s}^{2} 5 \mathrm{p}^{1}$ and $[\mathrm{Kr}] 4 \mathrm{~d}^{10} 5 \mathrm{~s}^{2} 5 \mathrm{p}^{4}$, respectively. In the energy span of $-15 \mathrm{eV}$ to $10 \mathrm{eV}$, the total density of state (TDOS) and partial density of state (PDOS) have been computed and shown in Fig. 2. At $0 \mathrm{GPa}$ pressure, Fig. 2 (a) shows the TDOS and PDOS for the $\mathrm{Zn}-4 \mathrm{~s} / 3 \mathrm{p} / 3 \mathrm{~d}$, In-5s/5p, and Te-5s/5p states, which reveals that the valence band is divided into three parts. The first portion is mostly made up of Te-5s, with a small amount of In-5s and In-5p states. The second portion is strongly localized, owing to the presence of $\mathrm{Zn}-3 \mathrm{~d}$ in $-7.46 \mathrm{eV}$ to $-6.44 \mathrm{eV}$ energy region. The valance band, which ranges from $-6.09 \mathrm{eV}$ to Fermi energy $\left(\mathrm{E}_{\mathrm{F}}=0 \mathrm{eV}\right)$, is the third and final part. Mainly In-5s/5p and Te-5s/5p states give rise to make the third part. Figure 2 (a) reveals that the 
valance band is primarily made up of $\mathrm{Zn}-4 \mathrm{~s}$, Te-5s, and Te-5p states, with In-5s and In-5p making a minor contribution. The major effect of In-5s/5p and Te-5s/5p, with an admixture of Zn-4s/3p/3d, forms the conduction band, which ranges from $1.90 \mathrm{eV}$ to $6.91 \mathrm{eV}$. The TDOS and PDOS for Hg6s/5p/5d, In-5s/5p and Te-5s/5p states has been shown in Fig. 2 (b). Figure 2 (b) shows that similar results have also been observed for $\mathrm{HgIn}_{2} \mathrm{Te}_{4}$ in the valence and conduction bands.

\subsection{Elastic properties}

Elastic parameters are essential parameters to convey the mechanical strength of any material. $\mathrm{XIn}_{2} \mathrm{Te}_{4}$ crystallizes in the tetragonal structure that comes under the Laue group T11 [4, 5]. Tetragonal Laue group T11 does not have an analytical formula to calculate elastic moduli as it contains off-diagonal shear elastic constant $C_{16}$. Due to this, seven elastic constants are obtained in the optimized structure. However, employing $C_{16}$ equals zero, seven elastic constants of the Laue group T11 can be transformed into six elastic constants of the Laue group T1. Laue group T1 has a well-known formula to calculate the elastic constant from its six elastic stiffness constants $C_{i j}$, i.e., $C_{11}, C_{12}, C_{13}, C_{33}, C_{44}$ and $C_{66}$. Transformation of seven elastic stiffness coefficients of Laue group T11 into six elastic stiffness coefficients of Laue group T1 can be obtained through rotation around the $\mathrm{z}$-axis with the angle given by following relations $[4,5]$ :

$$
\phi_{\kappa, \gamma}=\frac{1}{4} \arctan \left(\frac{4 C_{16}}{C_{11}-C_{12}-2 C_{66}}\right)
$$

The above Eq. (1) gives the values of $\phi_{\kappa}$ and $\phi_{\gamma}$ within the range $0<\phi<|\pi / 2|$, where $\phi_{\gamma}=\phi_{\kappa}+\pi / 4$. The value of $\phi_{\kappa}$ has been calculated using Eq. (1) and found to be $0.87^{\circ}$ for $\mathrm{ZnIn}_{2} \mathrm{Te}_{4}$ and $2.30^{\circ}$ for $\mathrm{HgIn}_{2} \mathrm{Te}_{4}$ at $0 \mathrm{GPa}$. Six independent elastic constants $C_{i j}$ of Laue group T1 
have been calculated using relations mentioned in Ref. [38, 39] by employing the LDA estimated seven elastic stiffness coefficients of Laue group T11 and angle $\phi_{\kappa}$. The values of these six coefficients, i.e., $C_{11}, C_{12}, C_{13}, C_{33}, C_{44}$ and $C_{66}$ have been calculated at $0,5,10,13$, and $14 \mathrm{GPa}$ pressures. For any stable tetragonal Laue group T1 crystal, all six independent elastic stiffness coefficients under pressure must fulfill the Born-Huang criteria as follows [40]:

$$
C_{11}-P>0 ; C_{44}-P>0 ; C_{11}-C_{12}-2 P>0 ;\left(C_{33}-P\right)\left(C_{11}+C_{12}\right)-2\left(C_{13}-P\right)^{2}>0
$$

The estimated values of $C_{i j}$ for $\phi_{\kappa}$ at five different pressures are presented in Table 2 for $\mathrm{XIn}_{2} \mathrm{Te}_{4}$.

Plots have also been drawn between $C_{i j}$ and pressure, and presented in Figs. 3 (a) and 3 (b), respectively, for $\mathrm{ZnIn}_{2} \mathrm{Te}_{4}$ and $\mathrm{HgIn}_{2} \mathrm{Te}_{4}$. Figure 3 shows that the values of $C_{i j}$ increase with the increasing pressure for both the materials. At $14 \mathrm{GPa}$, the value of $C_{i j}$ defies the stability criteria mentioned above of Eq. (2) and turns into an unstable form, which indicates that $\mathrm{XIn}_{2} \mathrm{Te}_{4}$ is stable up to $13 \mathrm{GPa}$ only. It has also been observed that the values of $C_{11}$ and $C_{33}$ are significantly higher than the values of $C_{12} C_{13}, C_{44}$ and $C_{66}$. This shows that the compounds are anisotropic and have more chances of shear deformation in the direction of a- and c- axes than compression deformation.

\begin{tabular}{|c|}
\hline Figs. 3 (a), 3 (b), and Fig. 3 \\
\hline Figs. 4 (a), 4 (b), and Fig. 4 \\
\hline Table 2 \\
\hline
\end{tabular}

Further, the value of elastic moduli of $\mathrm{ZnIn}_{2} \mathrm{Te}_{4}$ and $\mathrm{HgIn}_{2} \mathrm{Te}_{4}$, such as shear modulus $(G)$, bulk modulus $(B)$, Poisson's ratio $(v), B / G$, and Young's modulus $(E)$ have been calculated at $0,5,10,13$, and $14 \mathrm{GPa}$ using the relations given in Ref. [41]. The estimated values of these elastic moduli are presented in Table 2. The bulk modulus for $\mathrm{ZnIn}_{2} \mathrm{Te}_{4}$ and $\mathrm{HgIn}_{2} \mathrm{Te}_{4}$ is 
35.322 GPa and 33.742 GPa, respectively, based on the extended Cohen formula given in Ref. [3]. The calculated values of bulk modulus $B$ are in good agreement at $0 \mathrm{GPa}$. Elastic moduli ( $B, G$ and $E$ ) versus pressure plots are shown in Fig. 4 (a) and 4 (b) for $\mathrm{ZnIn}_{2} \mathrm{Te}_{4}$ and $\mathrm{HgIn}_{2} \mathrm{Te}_{4}$ respectively, which indicates that $B, G$ and $E$ increase with the increase of pressure. Frantsevich et al. [22, 42, 43] have proposed the critical limits of $v<0.33$ and $B / G<2.67$ for covalent (brittle) materials else it is ionic (ductile). The calculated values of $v$ and $B / G$ indicate that both the semiconductors are of covalent behavior at $0 \mathrm{GPa}$. However, violate the inequalities and show the ionic (ductile) behavior at 5, 10, 13, and 14 GPa pressures. The Zener shear anisotropy factor's value $(A)$ has been evaluated using the formula $A=2 C_{66} /\left(C_{11}-C_{12}\right)[44]$ and presented in Table 2. For an anisotropic material, the value should be $A \neq 1$ otherwise material said to be isotropic material. Our calculated values of $A$ also show the anisotropic character of both compounds.

Debye temperature $\left(\theta_{D}\right)$ is a constant that signifies the temperature of the highest form of a crystal's vibration, which is closely related to the specific heat and melting point of the compounds. Using data of $G$ and $B$, Debye temperature values $\left(\theta_{D}\right)$ have been estimated based on relations given in Ref. $[32,45]$. The calculated values of $\theta_{D}$ for $\mathrm{ZnIn}_{2} \mathrm{Te}_{4}$ and $\mathrm{HgIn}_{2} \mathrm{Te}_{4}$ have been presented in Table 2, together with the reported data [8]. The calculated value of $\theta_{D}$ for $\mathrm{ZnIn}_{2} \mathrm{Te}_{4}$ is found to be in fair agreement with reported values at $0 \mathrm{GPa}$ [8]. However, the known values of $\theta_{D}$ for $\mathrm{CdIn}_{2} \mathrm{Te}_{4}$ and at other pressure are not available for comparison.

\subsection{Optical properties}

The frequency dependence complex dielectric function $\varepsilon(\omega)\left\{=\varepsilon_{1}(\omega)+i \varepsilon_{2}(\omega)\right\}$ is a prominent part of optical properties, which derives all other optical parameters such as extinction 
coefficient $\alpha(\omega)$, reflectivity $R(\omega)$, refractive index $n(\omega)$, and energy loss function $L(\omega)$ using the relations mentioned in the literature [46-49]. The imaginary part $\varepsilon_{2}(\omega)$ of the complex dielectric function deals with the absorption of the incident photon, and the real part $\varepsilon_{1}(\omega)$ of the complex dielectric function concerns with the incident photons dispersion. The optical parameters such as the imaginary part $\varepsilon_{2}(\omega)$ and real part $\varepsilon_{1}(\omega)$ of complex dielectric function $\varepsilon(\omega)$ for $\mathrm{XIn}_{2} \mathrm{Te}_{4}$ have been estimated at $0,5,10$, and $13 \mathrm{GPa}$ pressures. Curves have also been plotted for $\varepsilon_{1}(\omega)$ and $\varepsilon_{2}(\omega)$ parameters in the energy range of $0-15 \mathrm{eV}$ and presented in Figs. 5 and 6 , respectively, for $\mathrm{ZnIn}_{2} \mathrm{Te}_{4}$ and $\mathrm{HgIn}_{2} \mathrm{Te}_{4}$. The peak values of $\varepsilon_{2}(\omega)$ and $\varepsilon_{1}(\omega)$ parameters in Figs. 5 and 6 are marked as 'X,' which shows that in most cases, the peaks move in the direction of the high energy zone (blue-shift) with a change of pressure from $0 \mathrm{GPa}$ to $5 \mathrm{GPa}$, $5 \mathrm{GPa}$ to $10 \mathrm{GPa}$, and $10 \mathrm{GPa}$ to $13 \mathrm{GPa}$. Further, the static dielectric constant $\varepsilon(0)$ has been calculated and presented in the last row of Table 2. A fair agreement has been found between them at $0 \mathrm{GPa}$ [50]; however, they await experimental verification at other pressures.

Figs. 5 (a), 5 (b), and Fig. 5

Figs. 6 (a), 6 (b), and Fig. 6

\section{Conclusions}

The first-principle study is executed effectively to calculate the electronic, elastic, and optical properties for defect-chalcopyrite $\mathrm{ZnIn}_{2} \mathrm{Te}_{4}$ and $\mathrm{HgIn}_{2} \mathrm{Te}_{4}$ semiconductors at 0, 5, 10, 13, and 14 GPa pressures. The estimated values of electronic parameters such as lattice parameter (a and c), energy bandgap $\left(\mathrm{E}_{\mathrm{g}}\right)$, anion displacement parameter $\left(U_{x}, U_{y}\right.$, and $\left.U_{z}\right)$, and bond lengths $\left(d_{X-T e}\right.$, $d_{I n^{1}-T e}$ and $\left.d_{I n^{2}-T e}\right)$ are presented in Table 1 , which agree well with available reported and experimental values. The band structure shows that both compounds are indirect semiconductors 
with an energy gap of $1.398 \mathrm{eV}$ and $1.101 \mathrm{eV}$, respectively, for $\mathrm{ZnIn}_{2} \mathrm{Te}_{4}$ and $\mathrm{HgIn}_{2} \mathrm{Te}_{4}$. The TDOS and PDOS plots of $\mathrm{ZnIn}_{2} \mathrm{Te}_{4} / \mathrm{HgIn}_{2} \mathrm{Te}_{4}$ demonstrate that $\mathrm{Zn} / \mathrm{Hg}$ has a marginal effect around the Fermi level. However, the Te-5s/5p and In-5s/5p states dominate in the forming of valance and conduction bands. The value of $C_{11}, C_{12}, C_{13}, C_{33}, C_{44}, C_{66}, G, B, E, A, v, B / G$ and $\theta_{D}$ have been estimated at $0,5,10,13$, and $14 \mathrm{GPa}$ pressures and summarized in Table 2 . The values of $C_{i j}$ indicate that $\mathrm{ZnIn}_{2} \mathrm{Te}_{4}$ and $\mathrm{HgIn}_{2} \mathrm{Te}_{4}$ are stable up to $13 \mathrm{GPa}$ and later becomes unstable. The calculated values of $v$ and $B / G$ for $\mathrm{ZnIn}_{2} \mathrm{Te}_{4}$ and $\mathrm{HgIn}_{2} \mathrm{Te}_{4}$ are smaller than the critical limits of 0.33 and 2.67 at $0 \mathrm{GPa}$, which demonstrate the covalent behavior. Moreover, the estimated data of $v$ and $B / G$ do not satisfy the criterion of critical limits at 5,10 , and $13 \mathrm{GPa}$, and hence show the presence of ionic behavior. The estimated values of static dielectric constant $\varepsilon(0)$ are listed in Table 2 at $0,5,10$, and 13 GPa pressures, which indicates that the values of $\varepsilon(0)$ increase with the increasing pressure. The calculated static dielectric constant data under three different pressures of 5, 10, and $13 \mathrm{GPa}$ are not available for comparison, as well as 12 elastic parameters and Debye temperature under four different pressures of 5,10,13, and $14 \mathrm{GPa}$ are stated for the first time which await for experimental verification. The predicted values are generally in strong alignment with experimental and previously reported values, demonstrating the importance of this computational work. The values of these parameters are critical for future technological applications, such as selecting substrate materials and designing integrated circuits (ICs) for electro-optic systems. The predictive description of the computational methodology introduced in the present work is of immense significance and will mentor the forthcoming studies of these properties of new defect-chalcopyrite materials belong to the $\mathrm{A}^{\mathrm{II}} \mathrm{B}_{2}{ }^{\mathrm{III}} \mathrm{C}_{4}{ }^{\mathrm{VI}}$ family. 


\section{Acknowledgment}

We express our sincere thanks to Prof. J. P. Pandey, Vice-Chancellor, M. M. M. University of Technology, Gorakhpur, for his continuous encouragement and motivation in conducting this work. The authors also thank Dr. Dharmendra Kumar and Dr. B. P. Pandey, M. M. M. University of Technology, Gorakhpur, for the valuable discussion for the presented results.

Conflict of interest The authors declare no conficts of interest.

\section{References}

1. Kumar, P., Soni, A., Bhamu, K.C., Sahariya, J.: Optoelectronic behavioral study of defectchalcopyrite semiconductors XGa2Te4(X $=\mathrm{Zn}, \mathrm{Cd})$. Materials Research Bulletin. 86, 131-138 (2017). https://doi.org/10.1016/j.materresbull.2016.10.012

2. Zhang, S., Shi, L.: Structural, electronic, elastic and lattice dynamical properties of CdIn2Te4 under pressure from first principle. International Journal of Modern Physics B. 31, 1850026 (2017). https://doi.org/10.1142/S0217979218500261

3. Mishra, S., Ganguli, B.: Electronic and optical properties of defect CdIn2Te4 chalcopyrite semiconductor: A first principle approach. Materials Chemistry and Physics. 173, 429437 (2016). https://doi.org/10.1016/j.matchemphys.2016.02.034

4. Gomis, O., Vilaplana, R., Manjón, F.J., Santamaría-Pérez, D., Errandonea, D., PérezGonzález, E., López-Solano, J., Rodríguez-Hernández, P., Muñoz, A., Tiginyanu, I.M., Ursaki, V. V.: High-pressure study of the structural and elastic properties of defectchalcopyrite HgGa2Se4. Journal of Applied Physics. 113, 0-10 (2013). https://doi.org/10.1063/1.4792495

5. Gomis, O., Santamaría-Pérez, D., Vilaplana, R., Luna, R., Sans, J.A., Manjón, F.J., Errandonea, D., Pérez-González, E., Rodríguez-Hernández, P., Muñoz, A., Tiginyanu, I.M., Ursaki, V.V.: Structural and elastic properties of defect chalcopyrite HgGa2S4 under high pressure. Journal of Alloys and Compounds. 583, 70-78 (2014).

https://doi.org/10.1016/j.jallcom.2013.08.123

6. Ouahrani, T., Reshak, A.H., Khenata, R., Amrani, B., Mebrouki, M., Otero-de-la-Roza, A., Luaña, V.: Ab-initio study of the structural, linear and nonlinear optical properties of CdAl2Se4 defect-chalcopyrite. Journal of Solid State Chemistry. 183, 46-51 (2010). https://doi.org/10.1016/j.jssc.2009.09.034 
7. Jiang, X., Lambrecht, W.R.L.: Electronic band structure of ordered vacancy defect chalcopyrite compounds with formula II-III2-VI4. Physical Review B. 69, 035201 (2004). https://doi.org/10.1103/PhysRevB.69.035201

8. Ganguli, B., Krishna Saha, K., Saha-Dasgupta, T., Mookerjee, A., Bhattacharya, A.K.: Electronic and optical properties of ZnIn2Te4. Physica B: Condensed Matter. 348, 382390 (2004). https://doi.org/10.1016/j.physb.2004.01.004

9. Bernard, J.E., Zunger, A.: Ordered-vacancy-compound semiconductors: Pseudocubic CdIn2Se4. Physical Review B. 37, 6835-6856 (1988). https://doi.org/10.1103/PhysRevB.37.6835

10. Errandonea, D., Kumar, R.S., Gomis, O., Manjón, F.J., Ursaki, V. V., Tiginyanu, I.M.: Xray diffraction study on pressure-induced phase transformations and the equation of state of ZnGa2Te4. Journal of Applied Physics. 114, (2013). https://doi.org/10.1063/1.4851735

11. Errandonea, D., Kumar, R.S., Manjón, F.J., Ursaki, V. V., Tiginyanu, I.M.: High-pressure $\mathrm{X}$-ray diffraction study on the structure and phase transitions of the defect-stannite ZnGa2Se4 and defect-chalcopyrite CdGa2S4. Journal of Applied Physics. 104, 063524 (2008). https://doi.org/10.1063/1.2981089

12. Gutiérrez, P.A., Sanjuán, M.L.: Ordinary and extraordinary phonons and photons: Raman study of anisotropy effects in the polar modes of MnGa2 Se4. Physical Review B. 78, 045212 (2008). https://doi.org/10.1103/PhysRevB.78.045212

13. You, S.H., Hong, K.J., Jeong, T.S., Youn, C.J., Park, J.S., Shin, D.C., Moon, J.D.: Band gap energy and valence band splitting of p-CdIn2Te 4 crystal by photocurrent spectroscopy. Journal of Applied Physics. 95, 4042-4045 (2004). https://doi.org/10.1063/1.1686901

14. Jeong, T.S., Hong, K.J.: Temperature dependence of intensity and peak position from photocurrent response in p-CdIn2Te4 crystal. Journal of Applied Physics. 96, 204-207 (2004). https://doi.org/10.1063/1.1758311

15. Misaki, T., Wakahara, A., Okada, H., Yoshida, A.: Epitaxial growth and characterization of ZnGeN2 by metalorganic vapor phase epitaxy. Journal of Crystal Growth. 260, 125129 (2004). https://doi.org/10.1016/j.jcrysgro.2003.08.011

16. Eifler, A., Riede, V., Hecht, J.-D., Krauss, G., Krämer, V., Grill, W.: On the Optical Properties of Defect-Chalcopyrite Single Crystals: The Aluminium Compounds HgAl2Se4, CdAl2Se4 and ZnAl2Se4. Japanese Journal of Applied Physics. 39, 98 (2000). https://doi.org/10.7567/JJAPS.39S1.98

17. Razzetti, C., Lottici, P.P.: Raman Scattering in Defective AIIB2IIIX4VI Compounds and Alloys. Japanese Journal of Applied Physics. 32, 431 (1993).

https://doi.org/10.7567/JJAPS.32S3.431 
18. Mayengbam, R., Tripathy, S.K., Palai, G., Dhar, S.S.: First-principles study of phase transition, electronic, elastic and optical properties of defect chalcopyrite $\mathrm{ZnGa} 2 \mathrm{Te} 4$ semiconductor under different pressures. Journal of Physics and Chemistry of Solids. 119, 193-201 (2018). https://doi.org/10.1016/j.jpcs.2018.03.027

19. Ayeb, Y., Ouahrani, T., Khenata, R., Reshak, A.H., Rached, D., Bouhemadou, A., Arrar, R.: FP-LAPW investigation of structural, electronic, linear and nonlinear optical properties of ZnIn2Te4 defect-chalcopyrite. Computational Materials Science. 50, 651655 (2010). https://doi.org/10.1016/j.commatsci.2010.09.030

20. Fuentes-Cabrera, M., Dong, J., Sankey, O.F.: Theoretical study of the structural, electronic and vibrational properties of CdIn2Te4. Thin Solid Films. 373, 19-22 (2000). https://doi.org/10.1016/S0040-6090(00)01082-8

21. Chandra, S., Kumar, V.: Structural, electronic and elastic properties of ZnGeN2 and WZ$\mathrm{GaN}$ under different hydrostatic pressures: A first-principle study. International Journal of Modern Physics B. 33, 1950297 (2019). https://doi.org/10.1142/S0217979219502977

22. Kumar, V., Chandra, S., Santosh, R.: First-Principles Calculations of the Structural, Electronic, Elastic and Optical Properties of LiGaS2 and LiGaSe2 Semiconductors Under Different Pressures. Journal of Electronic Materials. 47, 1223-1231 (2018). https://doi.org/10.1007/s11664-017-5894-x

23. Kumar, V., Singh, B.P., Pandey, B.P.: First-principle calculations of the elastic properties of semiconductors. Computational Materials Science. 87, 227-231 (2014). https://doi.org/10.1016/j.commatsci.2014.02.010

24. Srivastava, V.K.: Ionicity in AIIBIVCV2. Physical Review B. 36, 5044-5046 (1987). https://doi.org/10.1103/PhysRevB.36.5044

25. Kumar, V., Chandra, S.: Second-Order Nonlinear Optical Tensor Coefficients of LiXTe2 ( $\mathrm{X}=\mathrm{Al}, \mathrm{Ga}$, In) Chalcopyrite Semiconductors. Crystal Research and Technology. 53, 1800133 (2018). https://doi.org/10.1002/crat.201800133

26. Segall, M.D., Lindan, P.J.D., Probert, M.J., Pickard, C.J., Hasnip, P.J., Clark, S.J., Payne, M.C.: First-principles simulation: Ideas, illustrations and the CASTEP code. Journal of Physics Condensed Matter. 14, 2717-2744 (2002). https://doi.org/10.1088/0953$8984 / 14 / 11 / 301$

27. Ceperley, D.M., Alder, B.J.: Ground state of the electron gas by a stochastic method. Physical Review Letters. 45, 566-569 (1980). https://doi.org/10.1103/PhysRevLett.45.566

28. Perdew, J.P., Zunger, A.: Self-interaction correction to density-functional approximations for many-electron systems. Physical Review B. 23, 5048-5079 (1981). https://doi.org/10.1103/PhysRevB.23.5048

29. Hamann, D.R., Schlüter, M., Chiang, C.: Norm-Conserving Pseudopotentials. Physical Review Letters. 43, 1494-1497 (1979). https://doi.org/10.1103/PhysRevLett.43.1494 
30. Fischer, T.H., Almlöf, J.: General methods for geometry and wave function optimization. Journal of Physical Chemistry. 96, 9768-9774 (1992). https://doi.org/10.1021/j100203a036

31. Hahn, H., Frank, G., Klingler, W., Störger, A.D., Störger, G.: Untersuchungen über ternäre Chalkogenide. VI. Über Ternäre Chalkogenide des Aluminiums, Galliums und Indiums mit Zink, Cadmium und Quecksilber. Zeitschrift für anorganische und allgemeine Chemie. 279, 241-270 (1955). https://doi.org/10.1002/zaac.19552790502

32. Haynes, W.M., Lide, D.R., Bruno, T.J.: CRC Handbook of Chemistry and Physics, 97th Edition. (2017)

33. Suriwong, T., Kurosaki, K., Thongtem, S., Harnwunggmoung, A., Plirdpring, T., Sugahara, T., Ohishi, Y., Muta, H., Yamanaka, S.: Synthesis and thermal conductivities of ZnIn2Te4 and CdIn2Te4 with defect-chalcopyrite structure. Journal of Alloys and Compounds. 509, 7484-7487 (2011). https://doi.org/10.1016/j.jallcom.2011.04.086

34. Garbato, L., Ledda, F., Rucci, A.: Structural distortions and polymorphic behaviour in $\mathrm{ABC} 2$ and $\mathrm{AB} 2 \mathrm{C} 4$ tetrahedral compounds. Progress in Crystal Growth and Characterization. 15, 1-41 (1987). https://doi.org/10.1016/0146-3535(87)90008-6

35. Reguieg, S., Baghdad, R., Abdiche, A., Bezzerrouk, M.A., Benyoucef, B., Khenata, R., Bin-Omran, S.: First-Principles Study of Structural, Optical, and Thermodynamic Properties of ZnIn2X4 (X = Se, Te) Compounds with DC or DF Structure. Journal of Electronic Materials. 46, 401-412 (2017). https://doi.org/10.1007/s11664-016-4831-8

36. MacKinnon: Numerical Data and Functional Relationships in Science and Technology. In: Table of Numerical Data and Functional Relationships in Science and Technology. p. 124. Springer-Verilag, Berlin (1985)

37. Manca, P., Raga, F., Spiga, A.: Photoconductivity of ZnIn2Se4 and ZnIn2Te4. Physica Status Solidi (a). 16, K105-K108 (1973). https://doi.org/10.1002/pssa.2210160243

38. Farley, J.M., Saunders, G.A.: Ultrasonic study of the elastic behaviour of calcium tungstate between $1.5 \mathrm{~K}$ and $300 \mathrm{~K}$. Journal of Physics C: Solid State Physics. 5, 30213037 (1972). https://doi.org/10.1088/0022-3719/5/21/008

39. Farley, J.M., Saunders, G.A., Chung, D.Y.: The elastic constants of strontium molybdate (ultrasound velocity data). Journal of Physics C: Solid State Physics. 6, 2010-2019 (1973). https://doi.org/10.1088/0022-3719/6/12/004

40. Mouhat, F., Coudert, F.X.: Necessary and sufficient elastic stability conditions in various crystal systems. Physical Review B - Condensed Matter and Materials Physics. 90, 0-3 (2014). https://doi.org/10.1103/PhysRevB.90.224104

41. Caracas, R., Boffa Ballaran, T.: Elasticity of (K,Na)AlSi3O8 hollandite from lattice dynamics calculations. Physics of the Earth and Planetary Interiors. 181, 21-26 (2010). https://doi.org/10.1016/j.pepi.2010.04.004 
42. Frantsevich, I.N., Voronov, F.F., Bokuta, S.A.: Elastic Constants and Elastic Moduli of Metals and Insulators. , Naukova Dumka, Kiev (1982)

43. Vaitheeswaran, G., Kanchana, V., Kumar, R.S., Cornelius, A.L., Nicol, M.F., Svane, A., Delin, A., Johansson, B.: High-pressure structural, elastic, and electronic properties of the scintillator host material KMgF3. Physical Review B. 76, 014107 (2007).

https://doi.org/10.1103/PhysRevB.76.014107

44. Ouahrani, T., Reshak, A.H., Khenata, R., Amrani, B., Mebrouki, M., Otero-de-la-Roza, A., Luaña, V.: Ab-initio study of the structural, linear and nonlinear optical properties of CdAl2Se4defect-chalcopyrite. Journal of Solid State Chemistry. 183, 46-51 (2010). https://doi.org/10.1016/j.jssc.2009.09.034

45. Anderson, O.L.: A simplified method for calculating the debye temperature from elastic constants. Journal of Physics and Chemistry of Solids. 24, 909-917 (1963). https://doi.org/10.1016/0022-3697(63)90067-2

46. Tributsch, H.: Solar Energy-Assisted Electrochemical Splitting of Water. Some Energetical, Kinetical and Catalytical Considerations Verified on MoS2 Layer Crystal Surfaces. Zeitschrift für Naturforschung A. 32, (1977). https://doi.org/10.1515/zna-19770911

47. Wooten, F.: Optical Properties Of Solids. Academic Press. 260 (1972). https://doi.org/10.1016/0165-1633(89)90057-9

48. Dadsetani, M., Pourghazi, A.: Optical properties of strontium monochalcogenides from first principles. Physical Review B - Condensed Matter and Materials Physics. 73, 1-7 (2006). https://doi.org/10.1103/PhysRevB.73.195102

49. Sahin, S., Ciftci, Y.O., Colakoglu, K., Korozlu, N.: First principles studies of elastic, electronic and optical properties of chalcopyrite semiconductor ZnSnP2. Journal of Alloys and Compounds. 529, 1-7 (2012). https://doi.org/10.1016/j.jallcom.2012.03.046

50. Neumann, H., Kissinger, W., Lévy, F.: High-frequency dielectric constant of AIIB2IIIC4VI ordered-vacancy compounds. Crystal Research and Technology. 25, 11891193 (1990). https://doi.org/10.1002/crat.2170251015 
Table 1. Optimized values of lattice parameters $(\mathrm{a}=\mathrm{b}$ and $\mathrm{c})$, unit cell volume $\left(\mathrm{V}_{0}\right)$, internal parameters $\left(U_{x}, U_{y}\right.$ and $\left.U_{z}\right)$, bond lengths $\left(d_{X-T e}, d_{I n^{1}-T e}\right.$ and $\left.d_{I n^{2}-T e}\right)$, and energy bandgap $\left(\mathrm{E}_{\mathrm{g}}\right)$ for $\mathrm{ZnIn}_{2} \mathrm{Te}_{4}$ and $\mathrm{HgIn} \mathrm{Te}_{4}$ defect-chalcopyrite semiconductors.

\begin{tabular}{|c|c|c|c|c|c|c|c|c|c|c|c|}
\hline \multicolumn{2}{|c|}{ Compdounds. } & $a(\AA)$ & $c(\AA)$ & $\mathrm{V}_{0}\left(\AA^{3}\right)$ & $U_{x}$ & $U_{y}$ & $U_{z}$ & $d_{X-T e}(\AA)$ & $d_{I n^{1}-T e}(\AA)$ & $d_{I n^{2}-T e}(\AA)$ & $E_{g}(\mathrm{eV})$ \\
\hline \multirow{3}{*}{$\mathrm{ZnIn}_{2} \mathrm{Te}_{4}$} & This work & 6.045 & 12.044 & 434.517 & 0.270 & 0.218 & 0.137 & 2.655 & 2.734 & 2.726 & 1.398 \\
\hline & Expt. & $6.11^{\mathrm{a}}, 6.132^{\mathrm{b}}$ & $12.2^{\mathrm{a}}, 12.292^{\mathrm{b}}$ & & $0.26^{\mathrm{b}}$ & $0.24^{\mathrm{b}}$ & $0.13^{\mathrm{b}}$ & & & & $1.87-1.90^{\mathrm{c}}$ \\
\hline & Rep. & $\begin{array}{l}6.122^{\mathrm{d}}, 6.494^{\mathrm{e}}, \\
6.12^{\mathrm{f}}, 6.11^{\mathrm{g}} \\
\end{array}$ & $\begin{array}{l}12.24^{\mathrm{d}}, 12.887^{\mathrm{e}}, \\
12.24^{\mathrm{f}}, 12.22^{\mathrm{g}}\end{array}$ & & $\begin{array}{l}0.2485^{\mathrm{e}}, 0.261^{\mathrm{f}}, \\
0.25^{\mathrm{g}}, 0.269^{\mathrm{h}} \\
\end{array}$ & $\begin{array}{l}0.250^{\mathrm{e}}, 0.221^{\mathrm{f}}, \\
0.25^{\mathrm{g}}, 0.208^{\mathrm{h}}\end{array}$ & \begin{tabular}{|l|}
$0.1256^{\mathrm{e}}, 0.130^{\mathrm{f}}$ \\
$0.125^{\mathrm{g}}, 134^{\mathrm{h}}$
\end{tabular} & & & & $1.90^{\mathrm{i}}, 1.4^{\mathrm{j}}$ \\
\hline \multirow{3}{*}{$\mathrm{HgIn}_{2} \mathrm{Te}_{4}$} & This work & 6.125 & 12.084 & 446.833 & 0.277 & 0.225 & 0.141 & 2.757 & 2.736 & 2.726 & 1.101 \\
\hline & Expt. & $6.17^{\mathrm{a}}$ & $12.3^{\mathrm{a}}$ & & & & & & & & \\
\hline & Rep. & $6.186^{\mathrm{d}}$ & $12.37^{\mathrm{d}}$ & & & & & & & & $1.37^{\mathrm{i}}$ \\
\hline
\end{tabular}

${ }^{a}$ Reference [31], $\quad{ }^{b}$ Reference [33], $\quad{ }^{\mathrm{c}}$ Reference [36], $\quad{ }^{\mathrm{d}}$ Reference [32], $\quad{ }^{\mathrm{e}}$ Reference [19], $\quad{ }^{\mathrm{f}}$ Reference [34], $\quad{ }^{\mathrm{g}}$ Reference [8], $\quad{ }^{\mathrm{h}}$ Reference [35], $\quad{ }^{\mathrm{i}}$ Reference [7],

${ }^{\mathrm{j}}$ Refeernce [37]

Table 2. Calculated values of elastic constants $C_{i j}$ in GPa, bulk modulus $B$ in GPa, Shear modulus $G$ in GPa, Young's modulus $E$ in $\mathrm{GPa}$, Poisson's ratio $v, B / G$ ratio, Zener anisotropy factor $A$ and Debye temperature $\theta_{D}$ in ${ }^{\circ} \mathrm{K}$ under different pressure for $\mathrm{ZnIn}_{2} \mathrm{Te}_{4}$ and $\mathrm{HgIn}_{2} \mathrm{Te}_{4}$.

\begin{tabular}{|c|c|c|c|c|c|c|c|c|c|c|c|c|}
\hline \multirow{3}{*}{$\begin{array}{l}\text { Elastic } \\
\text { parameters }\end{array}$} & \multicolumn{6}{|c|}{$\mathrm{ZnIn}_{2} \mathrm{Te}_{4}$} & \multicolumn{6}{|c|}{$\mathrm{HgIn}_{2} \mathrm{Te}_{4}$} \\
\hline & \multicolumn{2}{|l|}{ At $0 \mathrm{GPa}$} & \multicolumn{4}{|c|}{ This work at } & \multicolumn{2}{|l|}{ At $0 \mathrm{GPa}$} & \multicolumn{4}{|c|}{ This work at } \\
\hline & This work & Rep. & $5 \mathrm{GPa}$ & $10 \mathrm{GPa}$ & $13 \mathrm{GPa}$ & $14 \mathrm{GPa}$ & This work & Rep. & $5 \mathrm{GPa}$ & $10 \mathrm{GPa}$ & $13 \mathrm{GPa}$ & $14 \mathrm{GPa}$ \\
\hline$C_{11}$ & 71.59 & & 101.15 & 129.06 & 125.87 & 138.56 & 61.27 & & 90.39 & 116.08 & 127.40 & 125.80 \\
\hline$C_{33}$ & 52.53 & & 81.88 & 95.77 & 107.90 & 109.51 & 53.19 & & 79.56 & 101.32 & 109.75 & 115.63 \\
\hline$C_{44}$ & 28.91 & & 36.00 & 39.14 & 30.35 & 22.46 & 24.32 & & 35.71 & 38.78 & 20.53 & 26.08 \\
\hline$C_{66}$ & 13.74 & & 20.63 & 19.79 & 38.35 & 24.08 & 13.06 & & 27.62 & 32.00 & 26.89 & 30.44 \\
\hline$C_{12}$ & 23.60 & & 49.05 & 65.69 & 94.78 & 88.69 & 19.90 & & 58.59 & 85.76 & 87.94 & 95.02 \\
\hline$C_{13}$ & 29.93 & & 52.34 & 74.22 & 85.67 & 90.80 & 27.62 & & 56.01 & 79.17 & 88.92 & 95.01 \\
\hline$B$ & 39.27 & $35.322^{*}$ & 64.44 & 85.21 & 97.27 & 101.28 & 35.61 & $33.742^{*}$ & 65.71 & 89.64 & 98.33 & 103.34 \\
\hline$G$ & 20.79 & & 26.40 & 27.15 & 24.60 & 21.24 & 18.48 & & 24.18 & 25.73 & 19.89 & 20.88 \\
\hline$E$ & 53.02 & & 69.69 & 73.64 & 68.07 & 59.57 & 47.26 & & 64.61 & 70.45 & 55.91 & 58.69 \\
\hline$v$ & 0.27 & & 0.32 & 0.36 & 0.38 & 0.40 & 0.28 & & 0.34 & 0.37 & 0.41 & 0.41 \\
\hline$B / G$ & 1.89 & & 2.44 & 3.14 & 3.95 & 4.77 & 1.93 & & 2.72 & 3.48 & 4.94 & 4.95 \\
\hline$A$ & 0.50 & & 0.67 & 0.55 & 1.93 & 0.85 & 0.56 & & 1.39 & 1.60 & 1.14 & 1.66 \\
\hline$\theta_{D}$ & 195.376 & $175^{\mathrm{g}, \$}$ & 221.411 & 225.617 & 215.569 & 200.824 & 172.736 & & 199.037 & 206.240 & 182.256 & 186.729 \\
\hline$\varepsilon(0)$ & 11.885 & $7.1 \pm 0.3^{\mathrm{a}}$ & 13.348 & 14.566 & 15.730 & & 10.407 & $8.55^{\mathrm{a}}$ & 11.860 & 13.076 & 13.756 & \\
\hline
\end{tabular}

a Reference [50], $\quad$ \$Experimental value, $\quad *$ Value calculated based upon extended Cohen formula given in Ref. [3] 


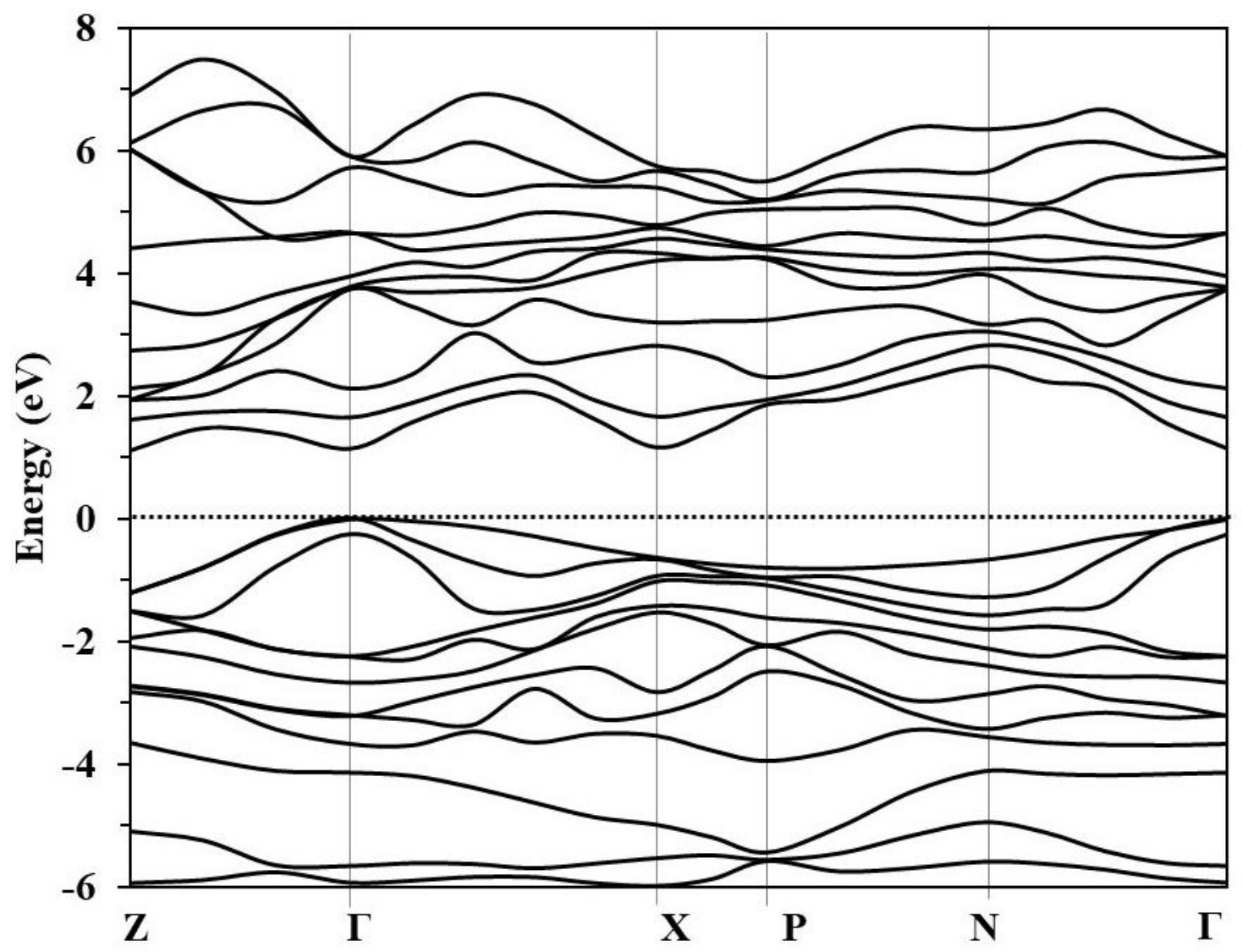

(a)

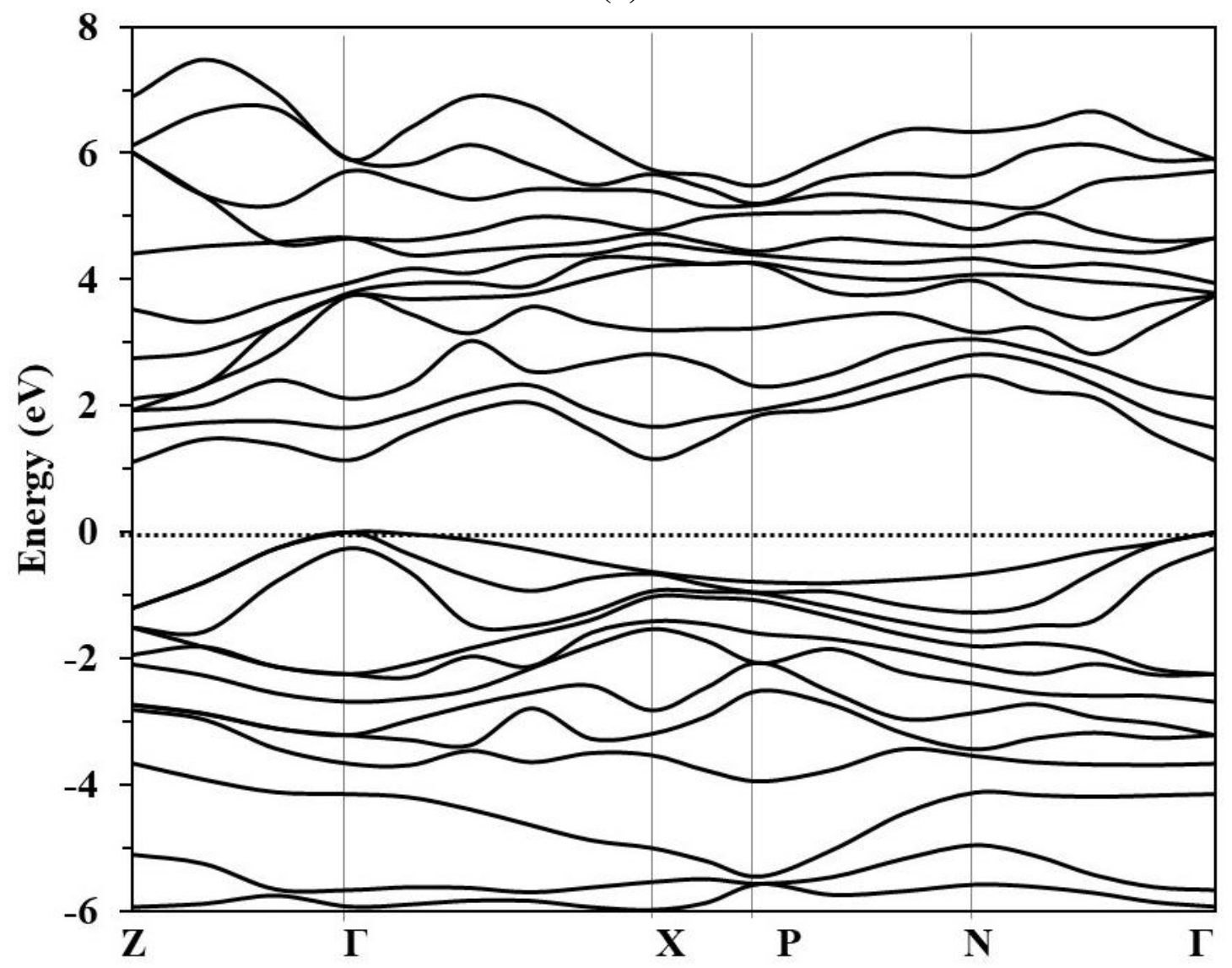

(b)

Fig. 1. Electronic band structure of (a) $\mathrm{ZnIn}_{2} \mathrm{Te}_{4}(1.398 \mathrm{eV})$ and (b) $\mathrm{HgIn}_{2} \mathrm{Te}_{4}(1.101 \mathrm{eV})$. 


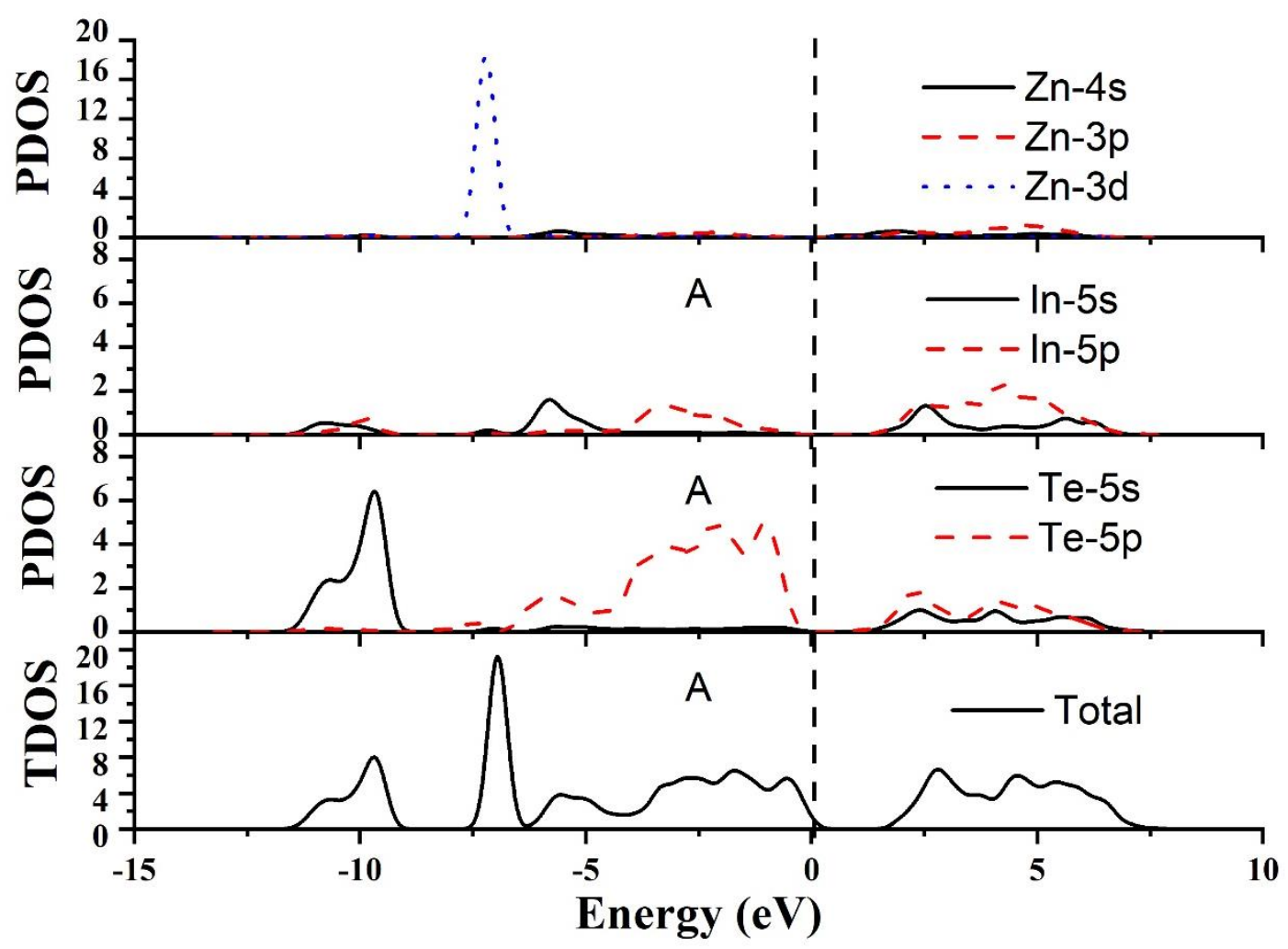

(a)



(b)

Fig. 2. DOS for (a) $\mathrm{ZnIn}_{2} \mathrm{Te}_{4}$ and (b) $\mathrm{HgIn}_{2} \mathrm{Te}_{4}$. 


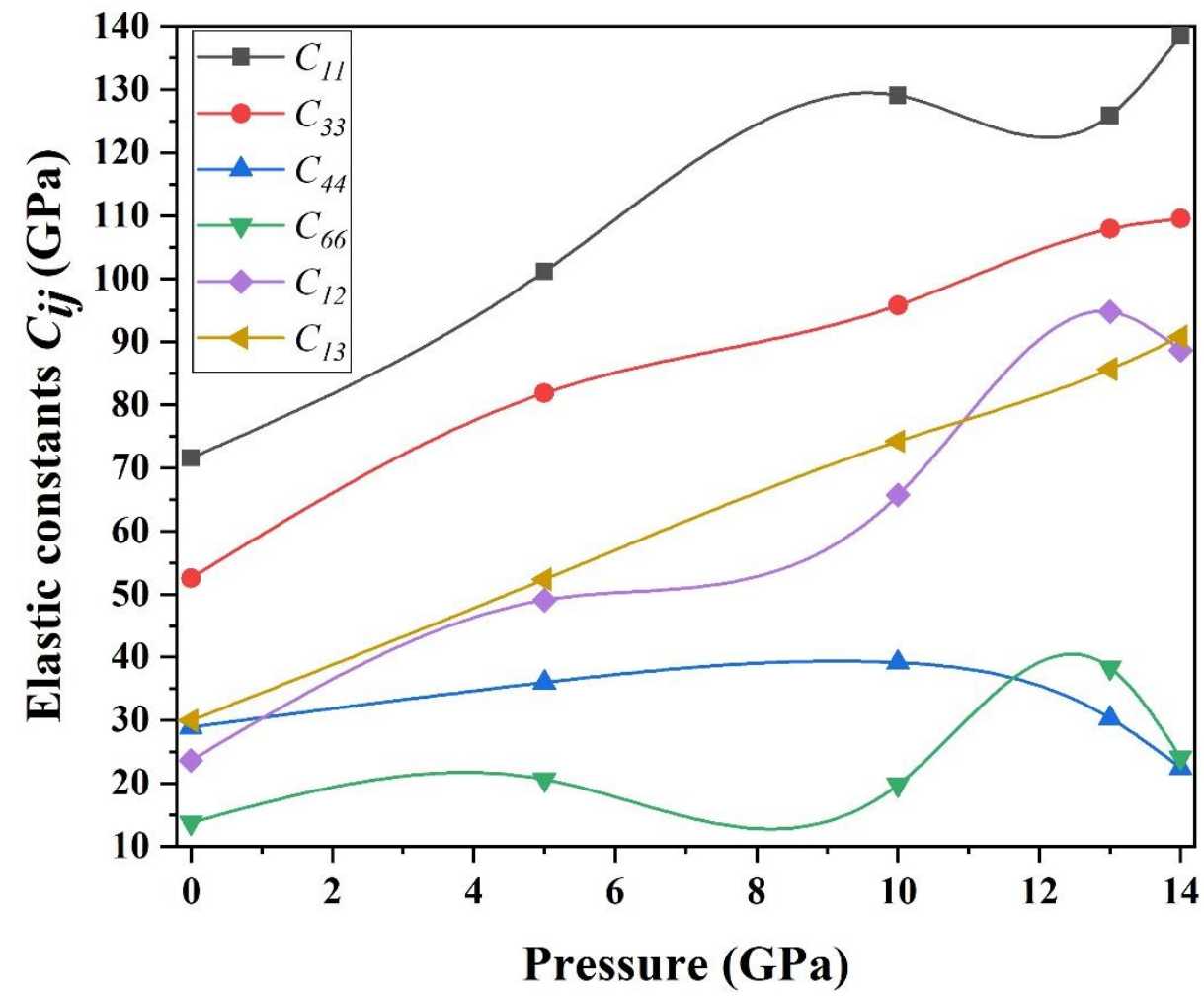

(a)

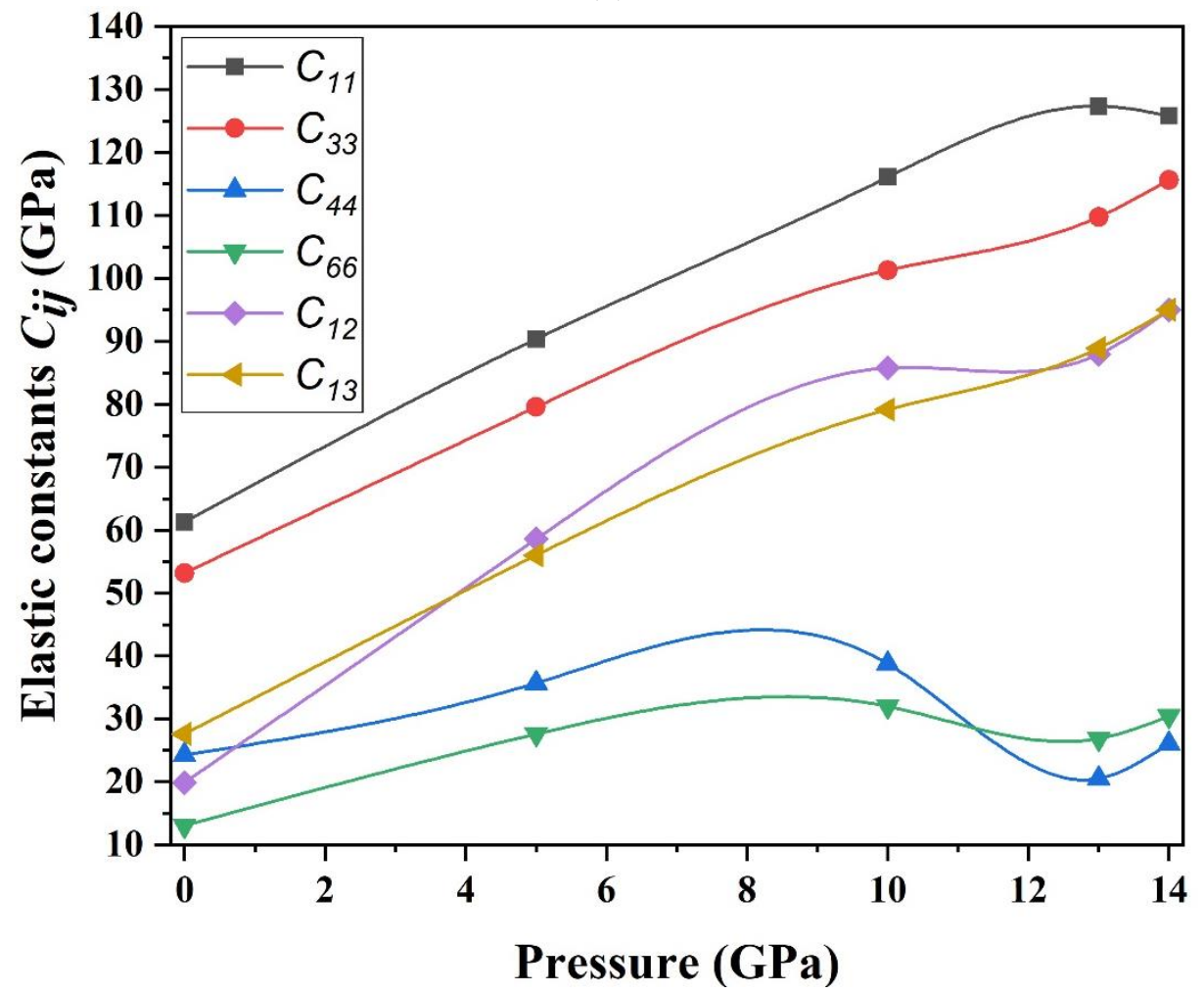

(b)

Fig. 3. Elastic constants vs pressure curve for (a) $\mathrm{ZnIn}_{2} \mathrm{Te}_{4}$ and (b) $\mathrm{HgIn}_{2} \mathrm{Te}_{4}$. 


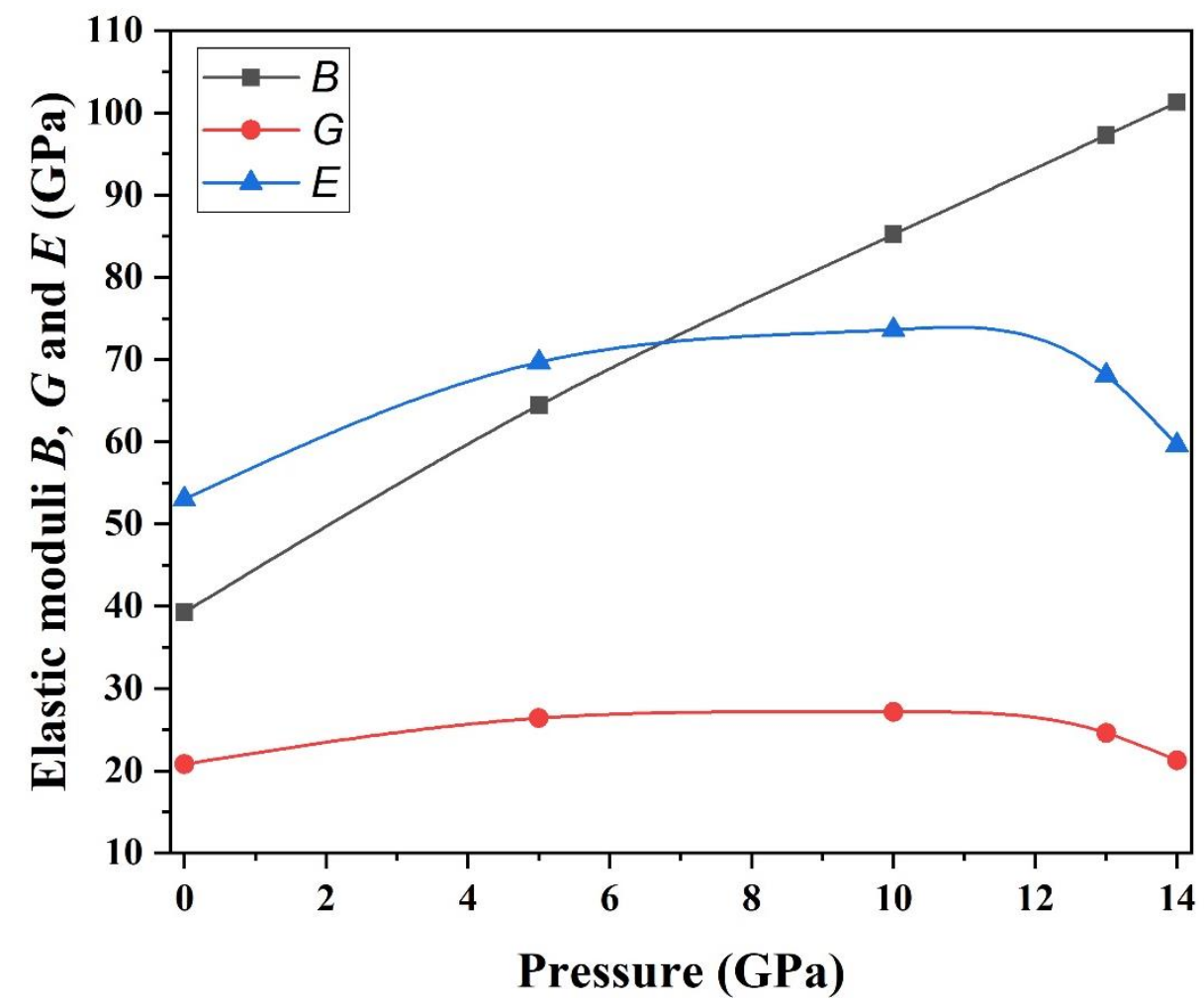

(a)



(b)

Fig. 4. (a) Elastic moduli vs pressure curve for (a) $\mathrm{ZnIn}_{2} \mathrm{Te}_{4}$ and (b) $\mathrm{HgIn}_{2} \mathrm{Te}_{4}$. 


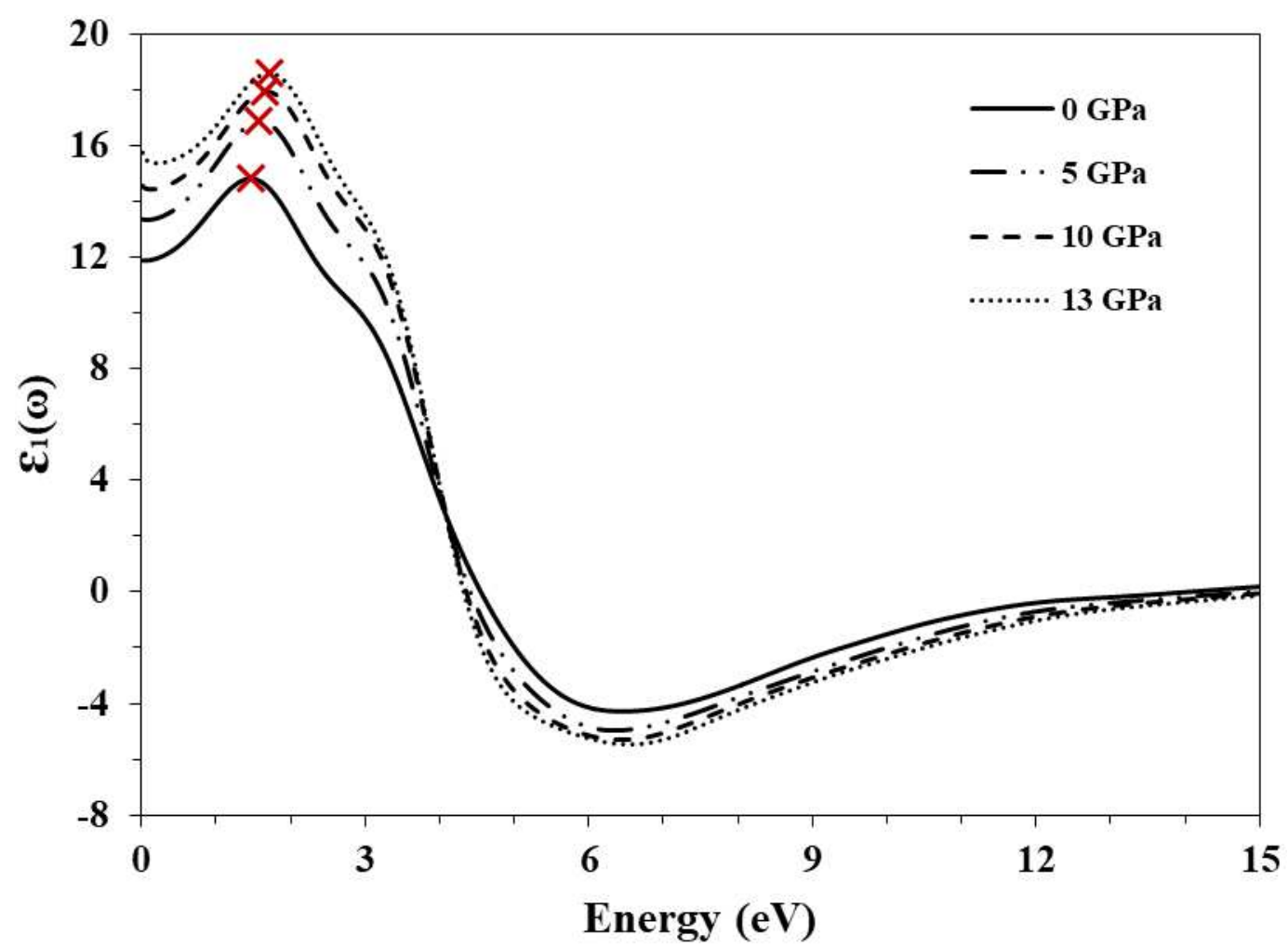

(a)

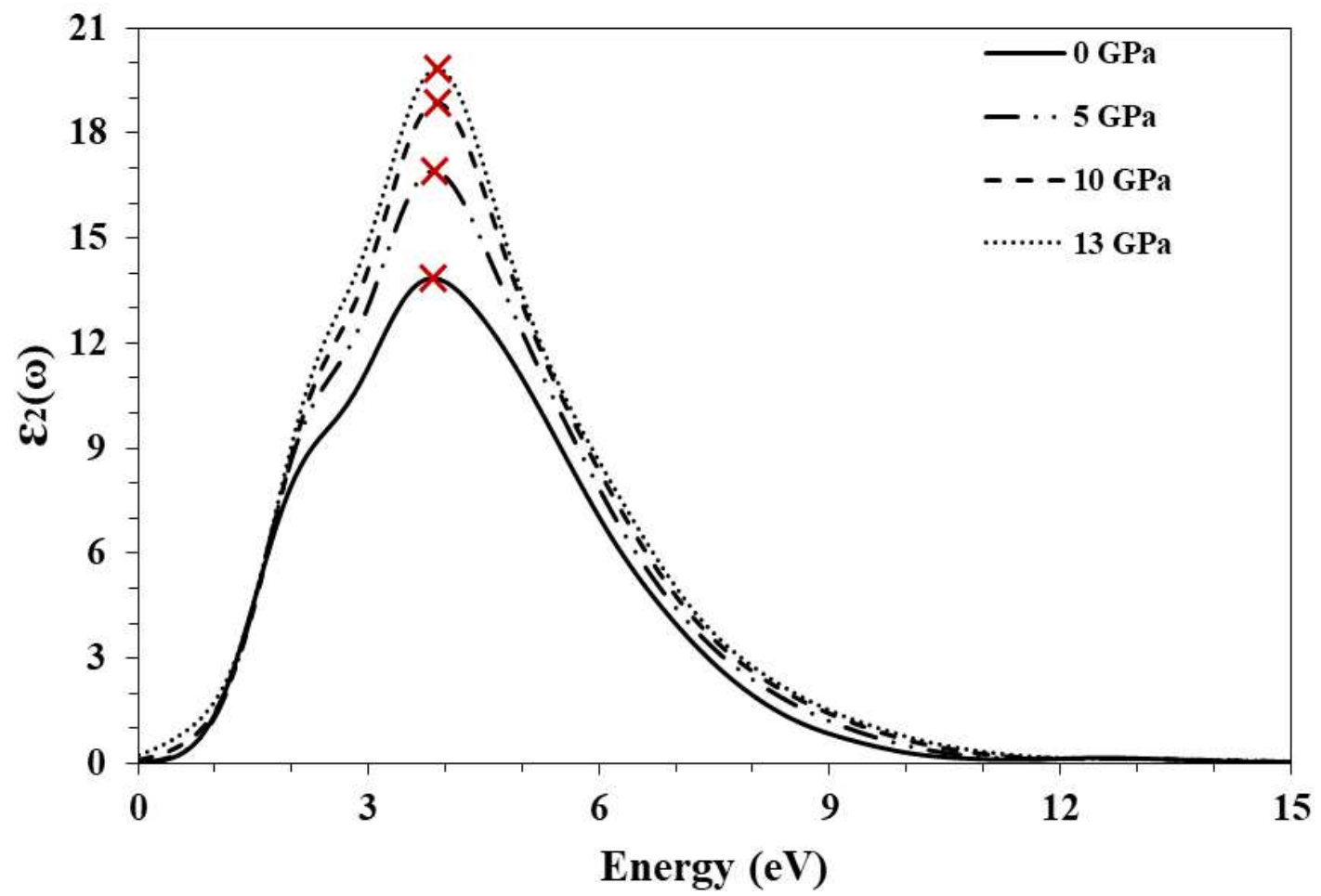

(b)

Fig. 5. Optical properties of $\mathrm{ZnIn}_{2} \mathrm{Te}_{4}$ : (a) real part dielectric function and (b) imaginary part of the dielectric function. 


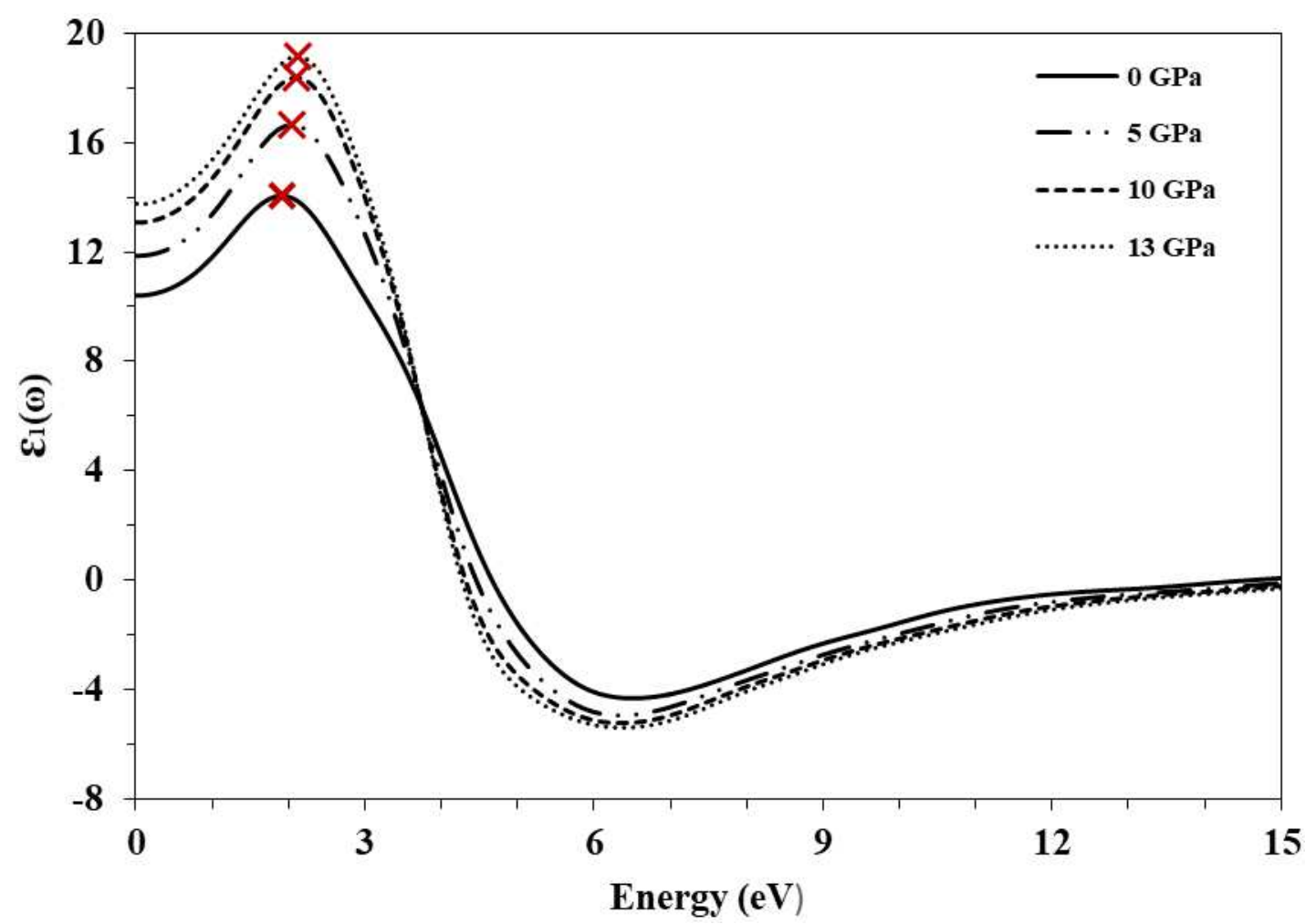

(a)

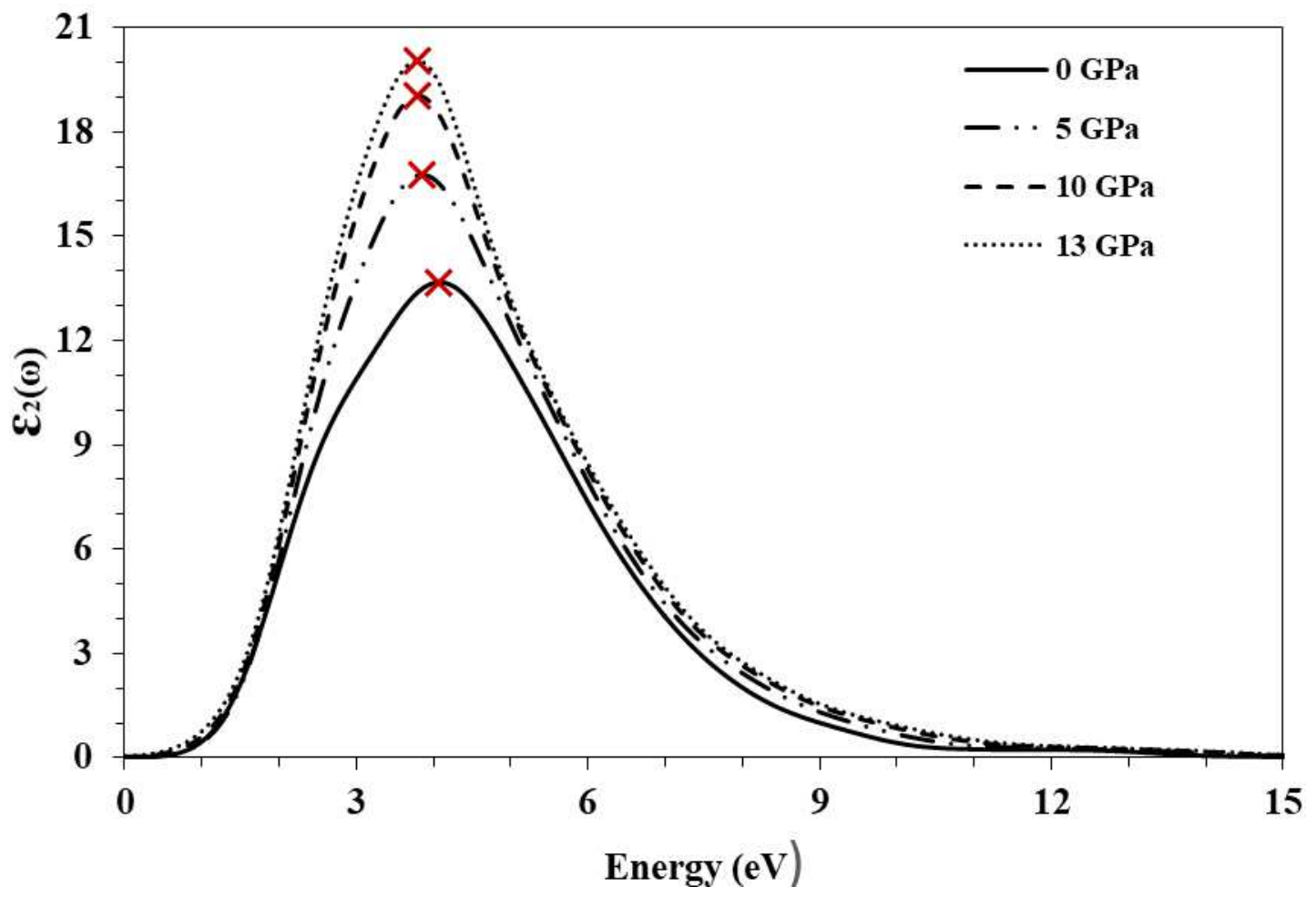

(b)

Fig. 6. Optical properties of $\mathrm{HgIn}_{2} \mathrm{Te}_{4}$ : (a) real part dielectric function and (b) imaginary part of the dielectric function. 